\title{
In Response to "Impact of Targeted Temperature Management on ED Patients with Drug Overdose-Related Cardiac Arrest"
}

\author{
John H. Fountain ${ }^{1} \cdot$ William Eggleston ${ }^{2,3}$ (1) \\ Received: 29 January 2019 / Revised: 5 February 2019 / Accepted: 13 February 2019 / Published online: 8 March 2019 \\ (C) American College of Medical Toxicology 2019
}

To the Editor:

We read with interest the article by Khan et al. [1] that retrospectively assessed the outcome of patients who received targeted temperature management (TTM) after a drug overdose-related cardiac arrest. The authors' primary finding was that incorporating TTM into post-arrest care was associated with improved survival. We agree with the authors' conclusion that this research provides important insight into the post-arrest management of patients with drug overdose and encourage further research on this topic. However, we would like to highlight another finding of this research that is an equally important consideration for patient care.

The patient demographic data reported by Khan et al. reveals a stark racial contrast between the patients that received TTM and the patients that did not receive TTM [1]. The TTM group contained 12 White patients and 17 non-White patients, while the non-TTM group contained 12 White patients and 78 non-White patients (data was not provided for 2 patients). Based on these data, White race was associated with a significantly higher likelihood of receiving TTM as a component of post-drug overdose arrest care (OR 4.59; 95\% CI, 1.76-11.95; $p=0.0018)$. This difference remained significant when comparing White race to all individual races reported, except for Hispanic race.

Previous research has suggested that patient race is associated with significant differences in the delivery of pa-

William Eggleston

WilliamDEggleston@gmail.com

1 SUNY Upstate Medical University, Syracuse, NY, USA

2 Department of Pharmacy Practice, Binghamton University School of Pharmacy and Pharmaceutical Sciences, Johnson City, NY, USA

3 Department of Emergency Medicine, SUNY Upstate Medical University, Syracuse, NY, USA tient care $[2,3]$. The results of this retrospective review support the concept that patient race may be associated with differences in drug overdose post-arrest care. Although it is not possible to assess all of the factors that influenced each patients' post-arrest care plan from a retrospective cohort, it is essential to consider the role race may have played in this process. As healthcare professionals, our goal must be to provide and increase access to highquality care for every patient. In order to attain this goal, we must first be able to recognize, deconstruct, and eliminate our own preconceived beliefs and biases.

Sources of Funding None.

\section{Compliance with Ethical Standards}

Conflicts of Interest None.

Publisher's Note Springer Nature remains neutral with regard to jurisdictional claims in published maps and institutional affiliations.

\section{References}

1. Khan S, Meyers CM, Bentley S, Manini AF. Impact of targeted temperature management on ED patients with drug overdoserelated cardiac arrest. J Med Toxicol 2019 Jan 1;15(1):22-29.

2. Arora S, Stouffer GA, Kucharska-Newton A, Vaduganathan M, Qamar A, Matsushita K, et al. Fifteen-year trends in management and outcomes of non-ST-segment-elevation myocardial infarction among black and white patients: the ARIC Community Surveillance Study, 2000-2014. J Am Heart Assoc. 2018 Oct 2;7(19):e010203.

3. Aparicio HJ, Carr BG, Kasner SE, Kallan MJ, Albright KC, Kleindorfer DO, et al. Racial disparities in intravenous recombinant tissue plasminogen activator use persist at primary stroke centers. $\mathrm{J}$ Am Heart Assoc. 2015 Oct 14;4(10):e001877. 